\title{
Molecular basis of natural variation and environmental control of trichome patterning
}

\author{
Marie-Theres Hauser* \\ Department of Applied Genetics and Cell Biology, University of Natural Resources and Life Sciences, Vienna, Austria
}

\section{Edited by: \\ Shucai Wang, Northeast Normal \\ University, China}

Reviewed by:

Crisanto Gutierrez, Consejo Superior de Investigaciones Cientificas, Spain

David G. Oppenheimer, University of Florida, USA

\section{${ }^{*}$ Correspondence:}

Marie-Theres Hauser, Department of Applied Genetics and Cell Biology, University of Natural Resources and Life Sciences, Muthgasse 18, A-1190 Vienna, Austria

e-mail: marie-theres.hauser@boku.ac.at
Trichomes are differentiated epidermal cells on above ground organs of nearly all land plants. They play important protective roles as structural defenses upon biotic attacks such as herbivory, oviposition and fungal infections, and against abiotic stressors such as drought, heat, freezing, excess of light, and UV radiation. The pattern and density of trichomes is highly variable within natural population suggesting tradeoffs between traits positively affecting fitness such as resistance and the costs of trichome production. The spatial distribution of trichomes is regulated through a combination of endogenous developmental programs and external signals. This review summarizes the current understanding on the molecular basis of the natural variation and the role of phytohormones and environmental stimuli on trichome patterning.

Keywords: trichome development, natural variation, OTL, GWAS, abiotic, biotic, defense

\section{INTRODUCTION}

Plants have evolved sophisticated morphological and chemical systems to cope with biotic and abiotic challenges. Differentiated epidermal cells such as leave hairs or trichomes represent one of these systems. Trichomes develop on above ground organs including seeds and fruits and occur in a large variety of morphologies. They can be single-celled or multicellular, branched or unbranched, and glandular or non-glandular, characteristics often used for species identification (Luckwill, 1943; Beilstein et al., 2006, 2008). Trichomes have a range of protective functions however producing them is costly, depend on plant resource availability and can have negative impacts on plant growth and vigor (Wilkens et al., 1996). Therefore trichome production often underlies qualitative and quantitative variation in most plant species.

\section{TRICHOMES AND ABIOTIC FACTORS}

In adverse environments, trichomes are beneficial because they influence the water balance, protect photosynthesis and reduce photoinhibition. Their density is negatively correlated with the rate of transpiration (Choinski and Wise, 1999; Benz and Martin, 2006) and that of carbon dioxide diffusion (Ehleringer et al., 1976; Galmés et al., 2007). The pubescent nature of plants growing in extreme alpine and Mediterranean habitats correlates with trichome's ability to protect the underlying tissue from sunlight by increasing the reflectance and reducing the heat load. Many plants accumulate also UV-absorbing compounds such as flavonols in trichomes which further protect the underlying photosynthetic tissues from damaging amount of UV-A and UV-B radiations (Karabourniotis et al., 1995, 1998; Karabourniotis and Bornman, 1999; Tattini etal., 2000, 2007; Morales et al., 2002; Liakopoulos et al., 2006; Yan etal., 2012). Evidence that trichomes are structural adaptations to low temperature and enhance tolerance to freezing came from studies on birch where frost increased rapidly the density of glandular trichomes (Prozherina et al.,
2003). Some heavy metal tolerant plants accumulate heavy metals in trichomes serving for detoxification purposes (Choi et al., 2001, 2004; Marmiroli et al., 2004; Freeman et al., 2006; Harada and Choi, 2008; Sarret et al., 2009; Quinn et al., 2010). Heavy metal loaded trichomes might contribute to elemental defense strategies (Boyd, 2012; Cheruiyot et al., 2013; Kazemi-Dinan et al., 2014).

\section{TRICHOMES AND BIOTIC CHALLENGES}

Many studies show that trichomes serve as physical barrier against biotic stressors such as insects, herbivores, fungal infections, and even parasitic plants (Peiffer et al., 2009; Runyon et al., 2010; Tian et al., 2012). Solanaceous species such as tomato and related species produce a variety of trichomes. The long multicellular type I trichomes that have a small glandular vesicle at the tip on hypocotyls for example effectively hinder the infection of tomato (Solanum lycopersicum) with its parasite Cuscuta pentagona (Runyon et al., 2010). Recent studies in several tomato wild relatives found that the presence, density, longevity and size of type I and the shorter multicellular type IV glandular trichomes correlates with resistance against whitefly (Firdaus et al., 2012, 2013). Oviposition and feeding experiments with the specialist moth Plutella xylostella on different Arabidopsis thaliana accessions showed that oviposition varied significantly among populations and could partly be explained by a negative relationship between trichome density and egg number, and a positive relationship between plant size and egg number (Handley et al., 2005). Experiment with glabrous and hairy Arabidopsis lyrata morphs and larvae of Plutella xylostella show that trichomes increased resistance to leaf damage and reduced oviposition in adult plants (Sletvold etal., 2010). However, in young plants that develop fewer trichomes this effect was not significant (Puentes and Agren, 2013). The larvae of the crucifer-feeding beetle, Phaedon brassicae, grew slower on hairy leaves of Arabidopsis halleri. Hairy leaves were less damaged when 
glabrous leaves were abundant in free choice experiments (Sato et al., 2014).

While non-glandular trichomes can be seen as structural defenses, glandular trichomes are also a source of highly interesting biomolecules (Shepherd etal., 2005; Liu etal., 2006; Kang etal., 2010). Apart from the above mentioned flavonols, glandular trichomes synthesize and/or store other highly valuable secondary metabolites such as terpenoids, phenylpropenes, methyl ketones (Fridman et al., 2005; Ben-Israel et al., 2009), acyl sugars (Schilmiller et al., 2012; Stout et al., 2012; Xu etal., 2013), and proteinase inhibitors (Tian etal., 2012) and thus contribute to the chemical repertoire of defense strategies. Given that trichomes provide both structural and chemical defense systems against herbivores and pathogens they are appealing targets for breeding (Gruber etal., 2006; Glas et al., 2012).

Controversial is the effect of trichomes for fungal infections: While damaged trichomes are often the starting point for colonialization with powdery mildew (Erysiphe necator) on grapevine buds (Rumbolz and Gubler, 2005), Botrytis cinerea on harvested tomato (Charles et al., 2008), Phoma clematidina on clematis (Van De Graaf et al., 2002) or Beauveria bassiana on poppy (Landa et al., 2013), glandular trichomes are often able to secrete exudates with antifungal activity as shown in a wild potato species (Solanum berthaultii) and its resistance to Phytophthora infestans (Lai et al., 2000). The disease incidence correlated negatively with the density and polyphenol-oxidase activity of short type A trichomes that have a four-lobed membrane-bound gland at their tips (Lai et al., 2000). In the infection of chickpea (Cicer arietinum) with Ascochyta rabiei the concentration of a highly acidic trichome exudate is crucial. At low concentrations the exudate promotes germination of Ascochyta rabiei conidia while at high concentrations germination is inhibited (Armstrong-Cho and Gossen, 2005). Also glandular trichomes of tobacco (Nicotiana tabacum) produce a potent inhibitor, T-phylloplanin, which inhibits germination of the oomycete Peronospora tabacina (Kroumova et al., 2007). The effect of trichomes is specific for the resistance to fungi. For example, while in Arabidopsis thaliana the infection with the soil-borne pathogen Rhizoctonia solani is not affected by trichome density, gll mutants were more resistant and the try mutant with clustered trichomes had an enhance colonialization with Botrytis cinerea (Calo et al., 2006). However, Arabidopsis thaliana transgenes expressing the antifungal $\alpha$-1,3-glucanase of Trichoderma harzianum in trichomes were more resistant to Botrytis cinerea demonstrating that trichomes can be engineered to increase resistance to fungal pathogens (Calo etal., 2006).

\section{REGULATION OF TRICHOME DENSITY IN Arabidopsis AND OTHER BRASSICACEAE}

Classical molecular genetic approaches of the model plant Arabidopsis thaliana identified major regulators of trichome development on leaves, stems and petiols. They fall into two classes: positive (mutants develop less trichomes) and negative regulators (mutants develop more and/or clusters of trichomes; for reviews see Balkunde et al., 2010). The positive regulators belong to three protein classes: a WD40 protein TRANSPARENT TESTA
GLABRA1 (TGG1; Galway et al., 1994; Walker et al., 1999), three R2R3 MYB-related transcription factors GLABRA1 (GL1, MYB23, MYB5; Oppenheimer et al., 1991; Kirik etal., 2005; Song et al., 2009; Tominaga-Wada et al., 2012) and four basic helix-loophelix (bHLH)-like transcription factors GLABRA3 (GL3; Payne et al., 2000), ENHANCER OF GLABRA3 (EGL3), TRANSPARENT TESTA (TT8; Zhang et al., 2003), and MYC-1 (Zhao et al., 2012). They act partially redundantly and form a multimeric activator complex, also known as MYB-bHLH-WD40 (MBW) complex which binds the promoter of GLABRA2 (GL2). GL2 encodes a homeodomain protein required for subsequent phases of trichome morphogenesis such as endoreduplication, branching, and maturation of the cell wall. The negative regulators are seven partially redundant single-repeat MYBs such as CAPRICE (CPC), TRIPTYCHON (TRY), ENHANCER OF TRY AND CPC 1, 2, 3 (ETC1, ETC2, ETC3), and TRICHOMELESS1 and 2 (TCL1, TCL2; Wester et al., 2009; Edgar et al., 2014; Wang and Chen, 2014). For most of them it has been shown that they act in a non-cell-autonomous manner. The single-repeat MYBs lack the C-terminal activation domain and inhibit the activator complex by replacing the R2R3 MYB-related transcription factors and thereby suppress trichome initiation in adjacent cells. While some of the positive and negative regulators are specific for trichome patterning others are also involved in root hair development, anthocyanin biosynthesis (Nemie-Feyissa et al., 2014), and seed coat mucilage production (Zhang et al., 2003; Song et al., 2009).

\section{HETEROBLASTY AND HORMONAL CONTROL OF TRICHOME DENSITY}

Trichome density is developmentally regulated. For example, Arabidopsis rosette leaves have trichomes only on the adaxial side and the number increases with the age of plants so that early leaves develop fewer and later more trichomes. On the other hand cauline leaves develop mainly abaxial and lack adaxial trichomes. This heteroblasty varies in different accessions (Larkin et al., 1996; Telfer et al., 1997; Gan et al., 2006; Hilscher et al., 2009) and is influenced by the photoperiod (Chien and Sussex, 1996).

Moreover hormones such as gibberellin (GA) promote trichome initiation and morphogenesis (Telfer et al., 1997; Perazza et al., 1998; Gan et al., 2006) by inducing GL1 expression. The original observation was that the GA biosynthesis mutant, gal3, develops less adaxial trichomes on leaves (Chien and Sussex, 1996) and application of GA restored and induces trichome production. Furthermore GA regulates also later stages in trichome development since mutants of the SPINDLY repressor of GA signaling not only develop glabrous sepals but also over-branched leaf trichomes (Perazza et al., 1998; Silverstone et al., 2007). For the effect of GA on trichome initiation on inflorescence organs four redundantly acting $\mathrm{C} 2 \mathrm{H} 2$ transcription factors have been identified: GLABROUS INFLORESCENCE STEMS (GIS, GIS2), ZINC FINGER PROTEIN 8 and 5 (ZFP8, ZFP5). They act upstream of GL1 and are involved in the action of cytokinin on trichome initiation (Gan et al., 2006, 2007a,b; Zhou et al., 2013).

As mentioned above trichomes can be induced by wounding and insect attack (Larkin et al., 1996; Yoshida et al., 2009) and the plant hormones involved in signaling these stresses 
are jasmonic acid (JA) and salicylic acid (Traw and Bergelson, 2003). Recently is has been shown that the JA receptor, CORONATINE-INSENSITVE1 (COI1), is involved in JA induced trichome production in tomato and Arabidopsis (Li et al., 2004; Qi et al., 2011) and that several repressors of JA signaling, JAZ1, $2,5,6,8,9,10,11$ are able to interact with components of the activator complex such as EGL3, GL3, TT8, MYB75, GL1 (Qi et al., 2011).

The positive effect of JA on trichome production is antagonized by salicylic acid. Reduced trichome development was observed after salicylic acid treatment or on mutants with elevated salicylic acid levels such as the CONSTITUTIVE EXPRESSION OF PR GENE (cpr) mutants (Bowling et al., 1997; Traw and Bergelson, 2003; An et al., 2011).

\section{NATURAL VARIATIONS AS SOURCE OF NOVEL TRICHOME REGULATORS}

Molecular analyses of natural variations of morphological and developmental traits have been a powerful approach to identify new genes important for adaptation to different environments (Assmann, 2013). For example the analyses of natural sequence variations of GL1 show that in particular the $3^{\prime}$ end is responsible for the glabrous phenotype of the Arabidopsis thaliana accession Mir-0, Br-0, Fran-3, PHW-2, 9354, Wil-2, Est as well as for hairless Arabidopsis lyrata, Arabidopsis halleri, Brassica rapa, Brassica oleracea, Brassica napus, and radish (Raphanus sativus) lines (Hauser et al., 2001; Kärkkäinen and Ågren, 2002; Kawagoe et al., 2011; Li et al., 2011, 2013; Bloomer et al., 2012). Larkin et al. (1993) has experimentally tested the importance of the non-coding $3^{\prime}$

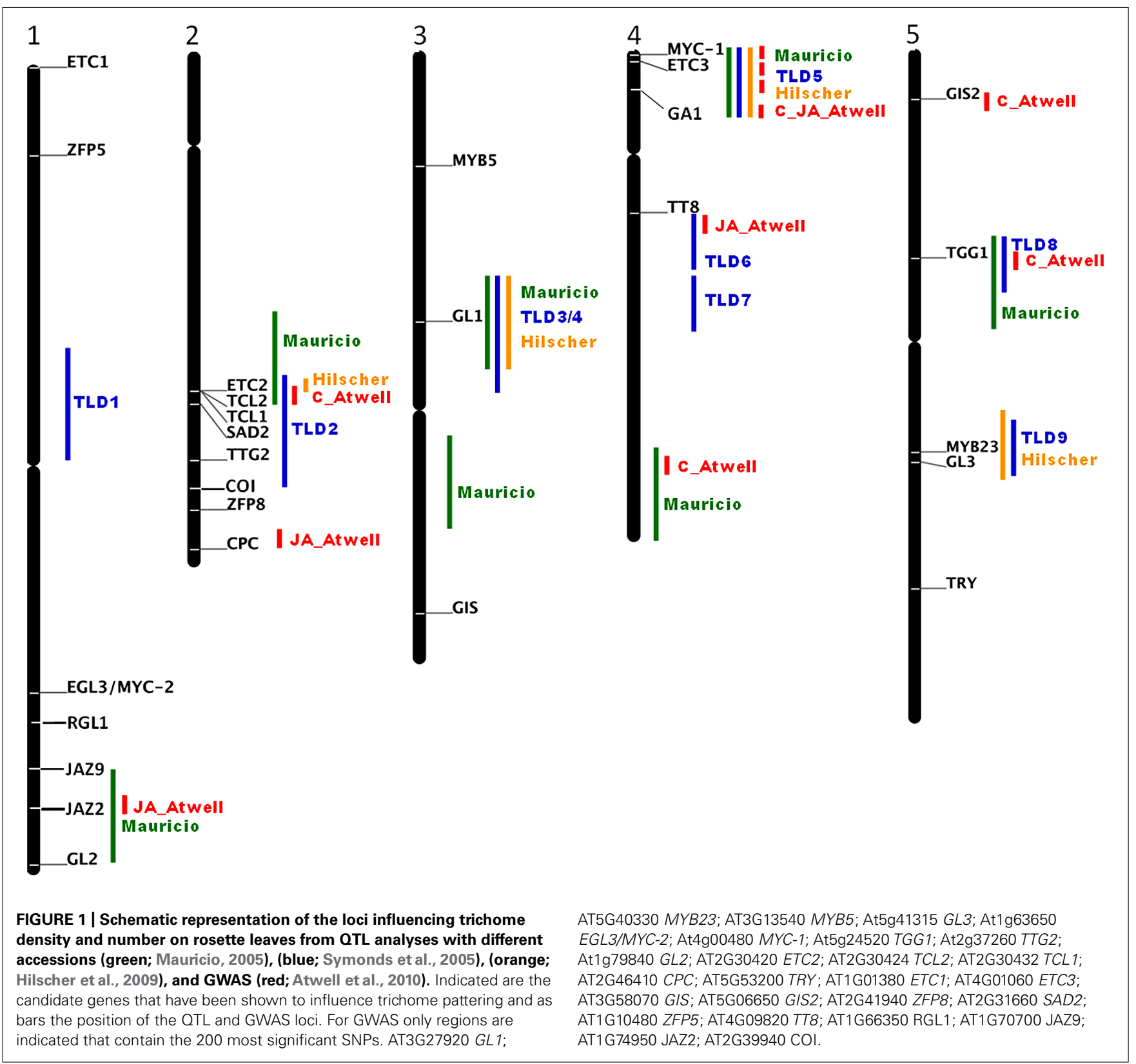


end and postulated that an enhancer downstream of the coding region is essential for the precise expression and function of GL1 in Arabidopsis. However, major phenotypic variations are rarely the effect of only one gene and its natural alleles, more frequently phenotypic variations in natural accessions depend on several partially interacting loci with quite small contributions. Their analysis needs statistical approaches such as quantitative trait locus (QTL) mapping. The first QTL analysis discovered a major locus, named REDUCED TRICHOME NUMBER (RTN) in Arabidopsis thaliana and used recombinant inbred lines (RIL) derived from a cross between the low trichome density Ler and the medium density Col-accessions (Larkin et al., 1996). This locus was identified in all further QTL analyses with combination of different accessions (Mauricio, 2005; Symonds et al., 2005; Bloomer et al., 2014) and even in a genome wide association study (GWAS; Atwell et al., 2010) as major regulator of trichome density. Hilscher et al. (2009) finally revealed RTN as ETC2 and the K19E amino acid substitution to be responsible for low trichome densities in natural Arabidopsis thaliana accessions. However, ETC2 is not the only gene responsible for trichome density variations. Mauricio (2005) and Symonds et al. (2005) identified each nine QTLs for trichome density in four recombinant inbred mapping populations of Arabidopsis thaliana. Most of the identified QTLs regions contain or are in close proximity of known trichome initiation regulators such as GL2, ETC2, TCL2, TCL1, SENSITIVE TO ABA AND DROUGHT2 (SAD2; Gao et al., 2008), TTG2, CPC, GL1, MYC-1, ETC3, GA1, TT8, GIS, TTG1, MYB23 and GL3. For MYC-1 a nonsynonymous substitution was identified in few accession which however did not correlate with trichome density (Symonds et al., 2011). While the sequence variation of ETC2, TCL2, TCL1, and GL1 have been studied the other candidate genes as well as genomic regions without candidate genes such as the loci TLD1 on chromosome 1, TLD6 and TLD7 in the middle of chromosome 3 and others identified with GWAS await closer examinations (Figure 1). With the availability of the 1001 Arabidopsis genomes association studies of the remaining candidate genes are now straight forward (Ossowski et al., 2008; Cao et al., 2011).

\section{OUTLOOK AND POTENTIAL OF UNDERSTANDING THE BASIS OF NATURAL VARIATIONS AND ENVIRONMENTAL INFLUENCES ON TRICHOME DENSITY REGULATION}

Although the major players of trichome density regulation have been identified in the model plant Arabidopsis they are still not sufficient to explain all the naturally occurring variations in this plants species. Great potential for the identification of still missing regulators will come from next generation sequencing possibilities in combination with classical genetic, population genetic and comparative approaches using different plant species. There are already several examples where trichome patterning regulators from wild relatives or even crops and distantly related species such as cotton, tomato and hop have been successfully and functionally studied in the model plant Arabidopsis (Wang et al., 2004; Guan et al., 2011; Kocábek and Matoušek, 2013; Tominaga-Wada et al., 2013). However, there are further needs for research determining the molecular basis of the patterning of different types of glandular trichomes and in particular of pharmaceutical and agronomically interesting plant species. Since trichomes serve as morphological, and in cases of glandular trichomes as chemical defense barriers against many abiotic stresses and biotic attacks, increasing their density has great potential to improve broad-spectrum pest and pathogen resistance in crops.

\section{ACKNOWLEDGMENTS}

Funding for this work was provided by grants from the Austrian Science Fund (FWF). The author thanks the anonymous reviewers for helpful comments.

\section{REFERENCES}

An, L., Zhou, Z., Yan, A., and Gan, Y. (2011). Progress on trichome development regulated by phytohormone signaling. Plant Signal. Behav. 6, 1959-1962. doi: 10.4161/psb.6.12.18120

Armstrong-Cho, C., and Gossen, B. D. (2005). Impact of glandular hair exudates on infection of chickpea by Ascochyta rabiei. Can. J. Bot. 83, 22-27. doi: 10.1139/b04147

Assmann, S. M. (2013). Natural variation in abiotic stress and climate change responses in Arabidopsis: implications for twenty-first-century agriculture. Int. J. Plant Sci. 174, 3-26. doi: 10.1086/667798

Atwell, S., Huang, Y. S., Vilhjálmsson, B. J., Willems, G., Horton, M., Li, Y., et al. (2010). Genome-wide association study of 107 phenotypes in Arabidopsis thaliana inbred lines. Nature 465, 627-631. doi: 10.1038/nature08800

Balkunde, R., Pesch, M., and Hülskamp, M. (2010). Trichome patterning in Arabidopsis thaliana: from genetic to molecular models. Curr. Top. Dev. Biol. 91, 299-321. doi: 10.1016/S0070-2153(10)91010-7

Beilstein, M. A., Al-Shehbaz, I. A., and Kellogg, E. A. (2006). Brassicaceae phylogeny and trichome evolution. Am. J. Bot. 93, 607-619. doi: 10.3732/ajb.93.4.607

Beilstein, M. A., Al-Shehbaz, I. A., Mathews, S., and Kellogg, E. A. (2008). Brassicaceae phylogeny inferred from phytochrome A and $n d h F$ sequence data: tribes and trichomes revisited. Am. J. Bot. 95, 1307-1327. doi: 10.3732/ajb. 0800065

Ben-Israel, I., Yu, G., Austin, M. B., Bhuiyan, N., Auldridge, M., Nguyen, T., et al. (2009). Multiple biochemical and morphological factors underlie the production of methylketones in tomato trichomes. Plant Physiol. 151, 1952-1964. doi: 10.1104/pp.109.146415

Benz, B. W., and Martin, C. E. (2006). Foliar trichomes, boundary layers, and gas exchange in 12 species of epiphytic Tillandsia (Bromeliaceae). J. Plant Physiol. 163, 648-656. doi: 10.1016/j.jplph.2005.05.008

Bloomer, R., Lloyd, A., and Symonds, V. (2014). The genetic architecture of constitutive and induced trichome density in two new recombinant inbred line populations of Arabidopsis thaliana: phenotypic plasticity, epistasis, and bidirectional leaf damage response. BMC Plant Biol. 14:119. doi: 10.1186/1471-2229-14-119

Bloomer, R. H., Juenger, T. E., and Symonds, V. V. (2012). Natural variation in GL1 and its effects on trichome density in Arabidopsis thaliana. Mol. Ecol. 21, 3501-3515. doi: 10.1111/j.1365-294X.2012.05630.x

Bowling, S. A., Clarke, J. D., Liu, Y., Klessig, D. F., and Dong, X. (1997). The cpr5 mutant of Arabidopsis expresses both NPR1-dependent and NPR1-independent resistance. Plant Cell 9, 1573-1584. doi: 10.1105/tpc.9.9.1573

Boyd, R. S. (2012). Plant defense using toxic inorganic ions: conceptual models of the defensive enhancement and joint effects hypotheses. Plant Sci. 195, 88-95. doi: 10.1016/j.plantsci.2012.06.012

Calo, L., García, I., Gotor, C., and Romero, L. C. (2006). Leaf hairs influence phytopathogenic fungus infection and confer an increased resistance when expressing a Trichoderma $\alpha$-1,3-glucanase. J. Exp. Bot. 57, 3911-3920. doi: $10.1093 / \mathrm{jxb} / \mathrm{erl} 155$

Cao, J., Schneeberger, K., Ossowski, S., Günther, T., Bender, S., Fitz, J., et al. (2011). Whole-genome sequencing of multiple Arabidopsis thaliana populations. Nat. Genet. 43, 956-965. doi: 10.1038/ng.911

Charles, M. T., Makhlouf, J., and Arul, J. (2008). Physiological basis of UV-C induced resistance to Botrytis cinerea in tomato fruit. II. Modification of fruit surface and changes in fungal colonization. Postharvest Biol. Technol. 47, 21-26. doi: 10.1016/j.postharvbio.2007.05.014

Cheruiyot, D. J., Boyd, R. S., and Moar, W. J. (2013). Exploring lower limits of plant elemental defense by cobalt, copper, nickel, and zinc. J. Chem. Ecol. 39, 666-674. doi: 10.1007/s10886-013-0279-y 
Chien, J. C., and Sussex, I. M. (1996). Differential regulation of trichome formation on the adaxial and abaxial leaf surfaces by gibberellins and photoperiod in Arabidopsis thaliana (L.) Heynh. Plant Physiol. 111, 1321-1328. doi: 10.1104/pp.111.4.1321

Choi, Y. E., Harada, E., Kim, G. H., Yoon, E. S., and Sano, H. (2004). Distribution of elements on tobacco trichomes and leaves under cadmium and sodium stresses. J. Plant Biol. 47, 75-82. doi: 10.1007/BF03030635

Choi, Y. E., Harada, E., Wada, M., Tsuboi, H., Morita, Y., Kusano, T., et al. (2001). Detoxification of cadmium in tobacco plants: formation and active excretion of crystals containing cadmium and calcium through trichomes. Planta 213, 45-50. doi: $10.1007 /$ s004250000487

Choinski, J. S. Jr., and Wise, R. R. (1999). Leaf growth and development in relation to gas exchange in Quercus marilandica Muenchh. J. Plant Physiol. 154, 302-309. doi: 10.1016/S0176-1617(99)80172-2

Edgar, B. A., Zielke, N., and Gutierrez, C. (2014). Endocycles: a recurrent evolutionary innovation for post-mitotic cell growth. Nat. Rev. Mol. Cell Biol. 15, 197-210. doi: $10.1038 / \mathrm{nrm} 3756$

Ehleringer, J., Björkman, O., and Mooney, H. A. (1976). Leaf pubescence: effects on absorptance and photosynthesis in a desert shrub. Science 191, 376-377. doi 10.1126/science.192.4237.376

Firdaus, S., Van Heusden, A. W., Hidayati, N., Supena, E. D. J., Mumm, R., De Vos, R. C. H., et al. (2013). Identification and QTL mapping of whitefly resistance components in Solanum galapagense. Theor. Appl. Genet. 126, 1487-1501. doi 10.1007/s00122-013-2067-z

Firdaus, S., Van Heusden, A. W., Hidayati, N., Supena, E. D. J., Visser, R. G. F., and Vosman, B. (2012). Resistance to Bemisia tabaci in tomato wild relatives. Euphytica 187, 31-45. doi: 10.1007/s10681-012-0704-2

Freeman, J. L., Zhang, L. H., Marcus, M. A., Fakra, S., Mcgrath, S. P., and Pilon-Smits, E. A. H. (2006). Spatial imaging, speciation, and quantification of selenium in the hyperaccumulator plants Astragalus bisulcatus and Stanleya pinnata. Plant Physiol. 142, 124-134. doi: 10.1104/pp.106. 081158

Fridman, E., Wang, J., Iijima, Y., Froehlich, J. E., Gang, D. R., Ohlrogge, J., et al. (2005). Metabolic, genomic, and biochemical analyses of glandular trichomes from the wild tomato species Lycopersicon hirsutum identify a key enzyme in the biosynthesis of methylketones. Plant Cell 17, 1252-1267. doi 10.1105/tpc.104.029736

Galmés, J., Medrano, H., and Flexas, J. (2007). Photosynthesis and photoinhibition in response to drought in a pubescent (var. minor) and a glabrous (var. palaui) variety of Digitalis minor. Environ. Exp. Bot. 60, 105-111. doi: 10.1016/j.envexpbot.2006.08.001

Galway, M. E., Masucci, J. D., Lloyd, A. M., Walbot, V., Davis, R. W., and Schiefelbein, J. W. (1994). The TTG gene is required to specify epidermal cell fate and cell patterning in the Arabidopsis root. Dev. Biol. 166, 740-754. doi: 10.1006/dbio.1994.1352

Gan, Y., Kumimoto, R., Liu, C., Ratcliffe, O., Yu, H., and Broun, P. (2006) GLABROUS INFLORESCENCE STEMS modulates the regulation by gibberellins of epidermal differentiation and shoot maturation in Arabidopsis. Plant Cell 18 1383-1395. doi: 10.1105/tpc.106.041533

Gan, Y., Liu, C., Yu, H., and Broun, P. (2007a). Integration of cytokinin and gibberellin signalling by Arabidopsis transcription factors GIS, ZFP8 and GIS2 in the regulations of epidermal cell fate. Development 134, 2073-2081. doi: 10.1242/dev.005017

Gan, Y., Yu, H., Peng, J., and Broun, P. (2007b). Genetic and molecular regulation by DELLA proteins of trichome development in Arabidopsis. Plant Physiol. 145 1031-1042. doi: 10.1104/pp.107.104794

Gao, Y., Gong, X., Cao, W., Zhao, J., Fu, L., Wang, X., et al. (2008). SAD2 in Arabidopsis functions in trichome initiation through mediating GL3 function and regulating GL1, TTG1 and GL2 expression. J. Integr. Plant Biol. 50, 906-917. doi: 10.1111/j.1744-7909.2008.00695.x

Glas, J. J., Schimmel, B. C. J., Alba, J. M., Escobar-Bravo, R., Schuurink, R. C., and Kant, M. R. (2012). Plant glandular trichomes as targets for breeding or engineering of resistance to herbivores. Int. J. Mol. Sci. 13, 17077-17103. doi 10.3390/ijms131217077

Gruber, M. Y., Wang, S., Ethier, S., Holowachuk, J., Bonham-Smith, P. C., Soroka, J., et al. (2006). "HAIRY CANOLA" - Arabidopsis GL3 induces a dense covering of trichomes on Brassica napus seedlings. Plant Mol. Biol. 60, 679-698. doi: 10.1007/s11103-005-5472-0
Guan, X., Lee, J. J., Pang, M., Shi, X., Stelly, D. M., and Chen, Z. J. (2011). Activation of Arabidopsis seed hair development by cotton fiber-related genes. PLoS ONE 6:e21301. doi: 10.1371/journal.pone.0021301

Handley, R., Ekbom, B., and Ågren, J. (2005). Variation in trichome density and resistance against a specialist insect herbivore in natural populations of Arabidopsis thaliana. Ecol. Entomol. 30, 284-292. doi: 10.1111/j.0307-6946.2005.00699.x

Harada, E., and Choi, Y. E. (2008). Investigation of metal exudates from tobacco glandular trichomes under heavy metal stresses using a variable pressure scanning electron microscopy system. Plant Biotechnol. 25, 407-411. doi: 10.5511/plantbiotechnology.25.407

Hauser, M., Harr, B., and Schlotterer, C. (2001). Trichome distribution in Arabidopsis thaliana and its close relative Arabidopsis lyrata: molecular analysis of the candidate gene GLABROUS1. Mol. Biol. Evol. 18, 1754-1763. doi: 10.1093/oxfordjournals.molbev.a003963

Hilscher, J., Schlotterer, C., and Hauser, M. T. (2009). A single amino acid replacement in ETC2 shapes trichome patterning in natural Arabidopsis populations. Curr. Biol. 19, 1747-1751. doi: 10.1016/j.cub.2009.08.057

Kang, J. H., Liu, G., Shi, F., Jones, A. D., Beaudry, R. M., and Howe, G. A. (2010). The tomato odorless-2 mutant is defective in trichome-based production of diverse specialized metabolites and broad-spectrum resistance to insect herbivores. Plant Physiol. 154, 262-272. doi: 10.1104/pp.110.160192

Karabourniotis, G., and Bornman, J. F. (1999). Penetration of UV-A, UV-B and blue light through the leaf trichome layers of two xeromorphic plants, olive and oak, measured by optical fibre microprobes. Physiol. Plant. 105, 655-661. doi: 10.1034/j.1399-3054.1999.105409.x

Karabourniotis, G., Kofidis, G., Fasseas, C., Liakoura, V., and Drossopoulos, I. (1998). Polyphenol deposition in leaf hairs of Olea europaea (Oleaceae) and Quercus ilex (Fagaceae). Am. J. Bot. 85, 1007-1012. doi: 10.2307/2446367

Karabourniotis, G., Kotsabassidis, D., and Manetas, Y. (1995). Trichome density and its protective potential against ultraviolet-B radiation damage during leaf development. Can. J. Bot. 73, 376-383. doi: 10.1139/b95-039

Kärkkäinen, K., and Ågren, J. (2002). Genetic basis of trichome production in Arabidopsis lyrata. Hereditas 136, 219-226. doi: 10.1034/j.1601-5223.2002.1360307.x

Kawagoe, T., Shimizu, K. K., Kakutani, T., and Kudoh, H. (2011). Coexistence of trichome variation in a natural plant population: a combined study using ecological and candidate gene approaches. PLOS ONE 6:e22184. doi: 10.1371/journal.pone.0022184

Kazemi-Dinan, A., Thomaschky, S., Stein, R. J., Krämer, U., and Müller, C. (2014) Zinc and cadmium hyperaccumulation act as deterrents towards specialist herbivores and impede the performance of a generalist herbivore. New Phytol. 202, 628-639. doi: 10.1111/nph.12663

Kirik, V., Lee, M. M., Wester, K., Herrmann, U., Zheng, Z., Oppenheimer, D., etal. (2005). Functional diversification of MYB23 and GL1 genes in trichome morphogenesis and initiation. Development 132, 1477-1485. doi: 10.1242/dev.01708

Kocábek, T., and Matoušek, J. (2013). Functional and complementation analysis of hop genes in heterologous systems. Acta Hortic. 1010, 77-84.

Kroumova, A. B., Shepherd, R. W., and Wagner, G. J. (2007). Impacts of T-phylloplanin gene knockdown and of Helianthus and Datura phylloplanins on Peronospora tabacina spore germination and disease potential. Plant Physiol. 144, 1843-1851. doi: 10.1104/pp.107.097584

Lai, A., Cianciolo, V., Chiavarini, S., and Sonnino, A. (2000). Effects of glandular trichomes on the development of Phytophthora infestans infection in potato (S. tuberosum). Euphytica 114, 165-174. doi: 10.1023/A:1003924318577

Landa, B. B., López-Díaz, C., Jiménez-Fernández, D., Montes-Borrego, M., Muñoz-Ledesma, F. J., Ortiz-Urquiza, A., et al. (2013). In-planta detection and monitorization of endophytic colonization by a Beauveria bassiana strain using a new-developed nested and quantitative PCR-based assay and confocal laser scanning microscopy. J. Invertebr. Pathol. 114, 128-138. doi: 10.1016/j.jip.2013.06.007

Larkin, J. C., Oppenheimer, D. G., Pollock, S., and Marks, M. D. (1993). Arabidopsis GLABROUS1 gene requires downstream sequences for function. Plant Cell 5, 1739-1748. doi: 10.1105/tpc.5.12.1739

Larkin, J. C., Young, N., Prigge, M., and Marks, M. D. (1996). The control of trichome spacing and number in Arabidopsis. Development 122, 997-1005.

Li, F., Kitashiba, H., and Nishio, T. (2011). Association of sequence variation in Brassica GLABRA1 orthologs with leaf hairiness. Mol. Breed. 28, 577-584. doi: 10.1007/s11032-010-9508-z 
Li, F., Zou, Z., Yong, H. Y., Kitashiba, H., and Nishio, T. (2013). Nucleotide sequence variation of GLABRA1 contributing to phenotypic variation of leaf hairiness in Brassicaceae vegetables. Theor. Appl. Genet. 126, 1227-1236. doi: 10.1007/s00122013-2049-1

Li, L., Zhao, Y., Mccaig, B. C., Wingerd, B. A., Wang, J., Whalon, M. E., et al. (2004). The tomato homolog of CORONATINE-INSENSITIVE1 is required for the maternal control of seed maturation, jasmonate-signaled defense responses, and glandular trichome development. Plant Cell 16, 126-143. doi: 10.1105/tpc.017954

Liakopoulos, G., Stavrianakou, S., and Karabourniotis, G. (2006). Trichome layers versus dehaired lamina of Olea europaea leaves: differences in flavonoid distribution, UV-absorbing capacity, and wax yield. Environ. Exp. Bot. 55, 294-304. doi: 10.1016/j.envexpbot.2004.11.008

Liu, J., Xia, K. F., Zhu, J. C., Deng, Y. G., Huang, X. L., Hu, B. L., et al. (2006). The nightshade proteinase inhibitor IIb gene is constitutively expressed in glandular trichomes. Plant Cell Physiol. 47, 1274-1284. doi: 10.1093/pcp/pcj097

Luckwill, L. C. (1943). The Genus Lycopersicon: An Historical, Biological, and Taxonomic Survey of the Wild and Cultivated Tomatoes. Aberdeen: Aberdeen University Press.

Marmiroli, M., Gonnelli, C., Maestri, E., Gabbrielli, R., and Marmiroli, N. (2004) Localisation of nickel and mineral nutrients $\mathrm{Ca}, \mathrm{K}, \mathrm{Fe}, \mathrm{Mg}$ by Scanning Electron Microscopy microanalysis in tissues of the nickel-hyperaccumulator Alyssum bertolonii Desv. and the non-accumulator Alyssum montanum L. Plant Biosyst. 138, 231-243. doi: 10.1080/11263500400011126

Mauricio, R. (2005). Ontogenetics of QTL: the genetic architecture of trichome density over time in Arabidopsis thaliana. Genetica 123, 75-85. doi: 10.1007/s10709-002-2714-9

Morales, F., Abadía, A., Abadía, J., Montserrat, G., and Gil-Pelegrín, E. (2002). Trichomes and photosynthetic pigment composition changes: responses of Quercus ilex subsp. ballota (Desf.) Samp. and Quercus coccifera L. to Mediterranean stress conditions. Trees 16, 504-510. doi: 10.1007/s00468-002-0195-1

Nemie-Feyissa, D., Olafsdottir, S. M., Heidari, B., and Lillo, C. (2014). Nitrogen depletion and small R3-MYB transcription factors affecting anthocyanin accumulation in Arabidopsis leaves. Phytochemistry 98, 34-40. doi: 10.1016/j.phytochem.2013.12.006

Oppenheimer, D. G., Herman, P. L., Sivakumaran, S., Esch, J., and Marks, M. D. (1991). A myb gene required for leaf trichome differentiation in Arabidopsis is expressed in stipules. Cell 67, 483-493. doi: 10.1016/0092-8674(91)90523-2

Ossowski, S., Schneeberger, K., Clark, R. M., Lanz, C., Warthmann, N., and Weigel, D. (2008). Sequencing of natural strains of Arabidopsis thaliana with short reads. Genome Res. 18, 2024-2033. doi: 10.1101/gr.080200.108

Payne, C. T., Zhang, F., and Lloyd, A. M. (2000). GL3 encodes a bHLH protein that regulates trichome development in Arabidopsis through interaction with GL1 and TTG1. Genetics 156, 1349-1362.

Peiffer, M., Tooker, J. F., Luthe, D. S., and Felton, G. W. (2009). Plants on early alert: glandular trichomes as sensors for insect herbivores. New Phytol. 184, 644-656. doi: 10.1111/j.1469-8137.2009.03002.x

Perazza, D., Vachon, G., and Herzog, M. (1998). Gibberellins promote trichome formation by up-regulating GLABROUS1 in Arabidopsis. Plant Physiol. 117, 375383. doi: 10.1104/pp.117.2.375

Prozherina, N., Freiwald, V., Rousi, M., and Oksanen, E. (2003). Interactive effect of springtime frost and elevated ozone on early growth, foliar injuries and leaf structure of birch (Betula pendula). New Phytol. 159, 623-636. doi: 10.1046/j.1469-8137.2003.00828.x

Puentes, A., and Ågren, J. (2013). Trichome production and variation in young plant resistance to the specialist insect herbivore Plutella xylostella among natural populations of Arabidopsis lyrata. Entomol. Exp. Appl. 149, 166-176. doi: 10.1111/eea.12120

Qi, T., Song, S., Ren, Q., Wu, D., Huang, H., Chen, Y., et al. (2011). The jasmonateZIM-domain proteins interact with the WD-repeat/bHLH/MYB complexes to regulate jasmonate-mediated anthocyanin accumulation and trichome initiation in Arabidopsis thaliana. Plant Cell 23, 1795-1814. doi: 10.1105/tpc.111. 083261

Quinn, C. F., Freeman, J. L., Reynolds, R. J., Cappa, J. J., Fakra, S. C., Marcus, M. A., et al. (2010). Selenium hyperaccumulation offers protection from cell disruptor herbivores. BMC Ecol. 10:19. doi: 10.1186/1472-6785-10-19

Rumbolz, J., and Gubler, W. D. (2005). Susceptibility of grapevine buds to infection by powdery mildew Erysiphe necator. Plant Pathol. 54, 535-548. doi: 10.1111/j.1365-3059.2005.01212.x
Runyon, J. B., Mescher, M. C., and De Moraes, C. M. (2010). Plant defenses against parasitic plants show similarities to those induced by herbivores and pathogens. Plant Signal. Behav. 5, 929-931. doi: 10.4161/psb.5.8.11772

Sarret, G., Willems, G., Isaure, M. P., Marcus, M. A., Fakra, S. C., Frérot, H., et al. (2009). Zinc distribution and speciation in Arabidopsis halleri $\times$ Arabidopsis lyrata progenies presenting various zinc accumulation capacities. New Phytol. 184, 581-595. doi: 10.1111/j.1469-8137.2009.02996.x

Sato, Y., Kawagoe, T., Sawada, Y., Hirai, M. Y., and Kudoh, H. (2014). Frequencydependent herbivory by a leaf beetle, Phaedon brassicae, on hairy and glabrous plants of Arabidopsis halleri subsp. gemmifera. Evol. Ecol. 28, 545-559. doi: 10.1007/s10682-013-9686-3

Schilmiller, A. L., Charbonneau, A. L., and Last, R. L. (2012). Identification of a BAHD acetyltransferase that produces protective acyl sugars in tomato trichomes. Proc. Natl. Acad. Sci. U.S.A. 109, 16377-16382. doi: 10.1073/pnas.1207906109

Shepherd, R. W., Bass, W. T., Houtz, R. L., and Wagner, G. J. (2005). Phylloplanins of tobacco are defensive proteins deployed on aerial surfaces by short glandular trichomes. Plant Cell 17, 1851-1861. doi: 10.1105/tpc.105.031559

Silverstone, A. L., Tseng, T. S., Swain, S. M., Dill, A., Sun, Y. J., Olszewski, N. E., et al. (2007). Functional analysis of SPINDLY in gibberellin signaling in Arabidopsis. Plant Physiol. 143, 987-1000. doi: 10.1104/pp.106.091025

Sletvold, N., Huttunen, P., Handley, R., Kärkkäinen, K., and Ågren, J. (2010). Cost of trichome production and resistance to a specialist insect herbivore in Arabidopsis lyrata. Evol. Ecol. 24, 1307-1319. doi: 10.1007/s10682-010-9381-6

Song, F. L., Milliken, O. N., Pham, H., Seyit, R., Napoli, R., Preston, J., et al. (2009). The Arabidopsis MYB5 transcription factor regulates mucilage synthesis, seed coat development, and trichome morphogenesis. Plant Cell 21, 72-89. doi: $10.1105 /$ tpc. 108.063503

Stout, J. M., Boubakir, Z., Ambrose, S. J., Purves, R. W., and Page, J. E. (2012). The hexanoyl-CoA precursor for cannabinoid biosynthesis is formed by an acyl-activating enzyme in Cannabis sativa trichomes. Plant J. 71, 353-365. doi: 10.1111/j.1365-313X.2012.04949.x

Symonds, V. V., Godoy, A. V., Alconada, T., Botto, J. F., Juenger, T. E., Casal, J. J., et al. (2005). Mapping quantitative trait loci in multiple populations of Arabidopsis thaliana identifies natural allelic variation for trichome density. Genetics 169, 1649-1658. doi: 10.1534/genetics.104.031948

Symonds, V. V., Hatlestad, G., and Lloyd, A. M. (2011). Natural allelic variation defines a role for ATMYC1: trichome cell fate determination. PLoS Genet. 7:e1002069. doi: 10.1371/journal.pgen.1002069

Tattini, M., Gravano, E., Pinelli, P., Mulinacci, N., and Romani, A. (2000). Flavonoids accumulate in leaves and glandular trichomes of Phillyrea latifolia exposed to excess solar radiation. New Phytol. 148, 69-77. doi: 10.1046/j.14698137.2000.00743.x

Tattini, M., Matteini, P., Saracini, E., Traversi, M. L., Giordano, C., and Agati, G. (2007). Morphology and biochemistry of non-glandular trichomes in Cistus salvifolius L. leaves growing in extreme habitats of the Mediterranean basin. Plant Biol. 9, 411-419. doi: 10.1055/s-2006-924662

Telfer, A., Bollman, K. M., and Poethig, R. S. (1997). Phase change and the regulation of trichome distribution in Arabidopsis thaliana. Development 124, 645-654.

Tian, D., Tooker, J., Peiffer, M., Chung, S. H., and Felton, G. W. (2012). Role of trichomes in defense against herbivores: comparison of herbivore response to woolly and hairless trichome mutants in tomato (Solanum lycopersicum). Planta 236, 1053-1066. doi: 10.1007/s00425-012-1651-9

Tominaga-Wada, R., Nukumizu, Y., Sato, S., Kato, T., Tabata, S., and Wada, T. (2012). Functional divergence of MYB-related genes, WEREWOLF and AtMYB23 in Arabidopsis. Biosci. Biotechnol. Biochem. 76, 883-887. doi: 10.1271/bbb.110811 Tominaga-Wada, R., Nukumizu, Y., Sato, S., and Wada, T. (2013). Control of plant trichome and root-hair development by a tomato (Solanum lycopersicum) R3 MYB transcription factor. PLoS ONE 8:e54019. doi: 10.1371/journal.pone.0054019

Traw, M. B., and Bergelson, J. (2003). Interactive effects of jasmonic acid, salicylic acid, and gibberellin on induction of trichomes in Arabidopsis. Plant Physiol. 133, 1367-1375. doi: 10.1104/pp.103.027086

Van De Graaf, P., Joseph, M. E., Chartier-Hollis, J. M., and O’Neill, T. M. (2002). Prepenetration stages in infection of clematis by Phoma clematidina. Plant Pathol. 51, 331-337. doi: 10.1046/j.1365-3059.2002.00727.x

Walker, A. R., Davison, P. A., Bolognesi-Winfield, A. C., James, C. M., Srinivasan, N., Blundell, T. L., et al. (1999). The TRANSPARENT TESTA GLABRA1 locus, which regulates trichome differentiation and anthocyanin biosynthesis 
in Arabidopsis, encodes a WD40 repeat protein. Plant Cell 11, 1337-1349. doi: 10.1105/tpc.11.7.1337

Wang, S., and Chen, J.-G. (2014). Regulation of cell fate determination by singlerepeat R3 MYB transcription factors in Arabidopsis. Front. Plant Sci. 5:133. doi: 10.3389/fpls.2014.00133

Wang, S., Wang, J.-W., Yu, N., Li, C.-H., Luo, B., Gou, J.-Y., et al. (2004). Control of plant trichome development by a cotton fiber MYB gene. Plant Cell 16, 2323 2334. doi: 10.1105/tpc.104.024844

Wester, K., Digiuni, S., Geier, F., Timmer, J., Fleck, C., and Hülskamp, M. (2009). Functional diversity of R3 single-repeat genes in trichome development. Development 136, 1487-1496. doi: 10.1242/dev.021733

Wilkens, R. T., Shea, G. O., Halbreich, S., and Stamp, N. E. (1996). Resource availability and the trichome defenses of tomato plants. Oecologia 106, 181-191. doi: 10.1007/BF00328597

Xu, H., Zhang, F., Liu, B., Huhman, D. V., Sumner, L. W., Dixon, R. A., et al. (2013). Characterization of the formation of branched short-chain fatty acid:CoAs for bitter acid biosynthesis in hop glandular trichomes. Mol. Plant 6, 1301-1317. doi: $10.1093 / \mathrm{mp} / \mathrm{sst} 004$

Yan, A., Pan, J., An, L., Gan, Y., and Feng, H. (2012). The responses of trichome mutants to enhanced ultraviolet-B radiation in Arabidopsis thaliana. J. Photochem. Photobiol. B Biol. 113, 29-35. doi: 10.1016/j.jphotobiol.2012.04.011

Yoshida, Y., Sano, R., Wada, T., Takabayashi, J., and Okada, K. (2009). Jasmonic acid control of GLABRA3 links inducible defense and trichome patterning in Arabidopsis. Development 136, 1039-1048. doi: 10.1242/dev.030585

Zhang, F., Gonzalez, A., Zhao, M., Payne, C. T., and Lloyd, A. (2003). A network of redundant bHLH proteins functions in all TTG1-dependent pathways of Arabidopsis. Development 130, 4859-4869. doi: 10.1242/dev.00681
Zhao, H., Wang, X., Zhu, D., Cui, S., Li, X., Cao, Y., et al. (2012). A single amino acid substitution in IIIf subfamily of basic helix-loop-helix transcription factor AtMYC1 leads to trichome and root hair patterning defects by abolishing its interaction with partner proteins in Arabidopsis. J. Biol. Chem. 287, 14109-14121. doi: 10.1074/jbc.M111.280735

Zhou, Z., Sun, L., Zhao, Y., An, L., Yan, A., Meng, X., et al. (2013). Zinc Finger Protein 6 (ZFP6) regulates trichome initiation by integrating gibberellin and cytokinin signaling in Arabidopsis thaliana. New Phytol. 198, 699-708. doi: $10.1111 /$ nph.12211

Conflict of Interest Statement: The author declares that the research was conducted in the absence of any commercial or financial relationships that could be construed as a potential conflict of interest.

Received: 04 May 2014; paper pending published: 06 June 2014; accepted: 17 June 2014; published online: 03 July 2014.

Citation: Hauser M-T (2014) Molecular basis of natural variation and environmental control of trichome patterning. Front. Plant Sci. 5:320. doi: 10.3389/fpls.2014. 00320

This article was submitted to Plant Cell Biology, a section of the journal Frontiers in Plant Science.

Copyright (C) 2014 Hauser. This is an open-access article distributed under the terms of the Creative Commons Attribution License (CC BY). The use, distribution or reproduction in other forums is permitted, provided the original author(s) or licensor are credited and that the original publication in this journal is cited, in accordance with accepted academic practice. No use, distribution or reproduction is permitted which does not comply with these terms. 